\title{
The Demographic Psychosocial Inventory: A New Instrument to Measure Risk Factors for Adjustment Problems Among Immigrants
}

\author{
Michael Ritsner, Jonathan Rabinowitz and Michael Slyuzberg ${ }^{1}$
}

\begin{abstract}
Objective-The purpose of this study was to develop and test the Demographic Psychosocial Inventory (DPSI), a self-report questionnaire that assesses demographic and background characteristics of immigrants, and psychosocial risk factors of demoralization.

Method-Based on a review of instruments used to study immigrants, and researchers' experience in this area, an 85-item questionnaire was developed that includes 10 scales and three general indices. Subjects are asked to indicate their level of satisfaction with various aspects of their lives, their reasons for immigration, and problems they had encountered since they immigrated.

Results-DPSI(Demographic Psychological Inventory) was tested on 1,200 adult immigrants who came to Israel from the former USSR since 1989. The reliability of the scales and general indices was generally high as measured by Cronbach's Alpha. For one general index and two scales it was above .78, for one general index and two scales it was between .60 and .73 , for one general index and two scales between .41 and .55 , and for one scale .23. The general indices were highly correlated with the Psychiatric Epidemiology Research Interview Demoralization Scale (PERI-D) and the Brief Symptom Inventory (BSI). The results suggest that the greatest risk factors of demoralization are a greater number of distress sources, difficulty in dealing with
\end{abstract}

Michael Ritsner, Talbieh Mental Health Center, Jerusalem, Israel.

Jonathan Rabinowitz and Michael Slyuzberg Bar-Ilan University School of Social Work, Ramat-Gan, Israel. conflict, greater discrepancy between actual difficulties encountered and those expected, and more reasons for immigration. The single most important variable in predicting a demoralization case was the number of distress sources. We developed DPSI cutting points for caseness based on comparisons to BSI and PERI-D. For the BSI, DPSI cutting points are .44 for males, and .48 for females. These cutting points recognize about $61 \%$ of those who are cases according to BSI, and about $72 \%$ of those who are not cases according to BSI. For the PERI-D, DPSI cutting points for caseness are .42 for males and .44 for females. These cutting points recognize about $63 \%$ of those who are demoralized according to PERI-D and about $68 \%$ of those who are not demoralized according to PERI-D. DPSI tends to recognize slightly more cases as being at risk of demoralization than those who are demoralized according to PERI-D, and slightly less than those identified as cases according to BSI.

Conclusions-DPSI is a promising instrument for gathering demographic and background characteristics of immigrants, and for studying psychosocial risk factors for development of demoralization. DPSI is available in English, Hebrew, and Russian.

\section{Background \\ Immigration and Mental Health Problems}

Immigration is a stressful event than can have long-lasting and far-reaching consequences leading to an increased risk of psychosocial problems (Rack 1988, Williams et al. 1991). Research has found that immigrants have higher rates of schizophrenia (Wijesinghe et al. 1991), hospitalization for mental ill- ness (Dean et al. 1981, Glover 1991, Harrison 1990), and increased risk of suicide (Stack 1981, Trovato 1986) and suicide ideation (Ponizovsky et al. 1994). Grove, Clayton, and Endicott (1986) found a stable connection between primary affective disorder and familial immigrant status. Beiser (1988) reports a similar connection between immigration and depression. Others have not confirmed this relationship (Noh et al. 1992).

Yet, while immigration unsettles the external and the internal world of the individual, it does not always lead to maladjustment (Grinberg et al. 1989, Scott et al. 1989). Rather, individual factors moderate the level of adjustment in immigration. Among these factors are: personal and social premigration problems, e.g., refugees who went through traumatic experiences and psychological distress (Grinberg et al. 1989, Scott et al. 1989); post-migration factors (i.e., unemployment and economical problems) (Jayasuriya et al. 1992); and the culture gap between the country of origin and the country of immigration (the greater the gap, the greater the risk of adjustment problems) (Berry 1979). An additional risk factor is the loss of occupational status, which may affect the self-esteem of immigrants and often result in depressive reactions (Berry 1979, Grinberg et al. 1989, Itzigsohn et al. 1989, Jayasuriya et al. 1992, Scott et al. 1989).

The resilience factors include the immigrant's attitude towards migration and towards the host country, motivation for immigration, and the extent to which immigration was voluntary (Grinberg et al. 1989, Jayasuriya et al. 1992, Scott et al. 1989), the level of identification with the host culture and 
its values (Epstein 1992), and re-establishment of a social network (Kuo et al. 1986).

The recent increase in immigration has been accompanied by studies of psychiatric symptomatology associated with immigration. For example, recent studies have focused on Iranians in Canada (Bagheir 1992), Arabs in the United States (May 1992), Latinos in the United States (Ring et al. 1991), Greeks in London (Mavreas et al. 1990), Mexicans in the United States (Rodriguez et al. 1990), Turks in Germany (Weyerer et al. 1992), and Koreans in Canada (Noh et al. 1992).

Proportionate to the size of the country, the mass immigration of Jews from the former USSR to Israel, which started in 1989 and has been ongoing since, has been one of the largest immigrations in modern history. It presents the State of Israel with the challenge of integrating about 500,000 new immigrants, which is over $10 \%$ of Israel's original population. As the influx of immigrants grew, it became evident that in addition to catering to employment and housing needs, attention had to be given to the psychological adjustment and wellbeing of the immigrants. Elevated levels of psychological distress among these immigrants were first noted through informal community channels and through the mass media. Increasing numbers of immigrants applied for treatment in mental health clinics, despite their culturallydetermined reluctance to seek help from mental health professionals (Brodsky 1988, Levav et al. 1990).

The yearly psychiatric admission rate for new immigrants to Israel in 1990-91 was about $35 \%$ higher than for the general population (Horowitz et al. 1992). According to clinical reports, emotional reactions of depressive colouring, ranging from mild to severe, seemed prevalent among Soviet immigrants. Indeed, $20.6 \%$ of the new immigrants admitted during 1990-91 into psychiatric hospitals were diagnosed as suffering from depression, as compared to $13.4 \%$ of veteran Israelis admitted during the same period (Horowitz et al. 1992). About twice as many Soviet immigrants to Israel have sought mental health services than they had when they were still in Russia (Levav et al. 1990).

Several studies have focused on Soviet Jewish immigrants to Israel and the United States. The studies suggest varying degrees of negative effects and some positive effects. Many of these studies have measured levels of demoralization using the Psychiatric Epidemiology Research Interview Demoralization Scale (PERI-D), which is a measure of nonspecific psychological distress. Soviet immigrants in Israel and the U.S. were found to be more demoralized than the indigenous population (Flaherty et al. 1986, 1988; Lerner et al. 1991; Ritsner et al. 1993). Soviet immigrants to the U.S. were more demoralized than those to Israel (Flaherty et al. 1988). Flaherty (1986) found that demoralization levels among Soviet immigrants to Chicago increased during the first three or four years in the U.S. and then tapered off, and that they were highest among older individuals, women, and those with weak social support systems. Similarly, Ritsner and Ginath (1994) found higher levels of demoralization among Soviet immigrants aged 55 to 64 than immigrants younger or older, and higher levels among females than males. The effect of age on increased demoralization was confirmed in another study that also found concomitant increases in depression and somatization (Kohn et al. 1989).

The relationship between depression and psychosomatic disorders among immigrants, and how such problems by parents affect children's adaptation, was explored among Soviet Jewish immigrants to Canada (Barankin et al. 1989). Immigrants with depression and psychosomatic illness reported greater behavioural, academic, peer-interaction, and child-parent difficulties in their children. Those who were married, were proficient in English, were professionals, and had supportive friends, were more likely to adapt well. Among the positive effects of immigration was greater cohesiveness among married couples as they faced common difficulties in a strange environment (Hartman et al. 1986).

Mental health professionals in Israel have become alerted to the needs of Soviet immigrants and growing efforts are being devoted to providing treatment, primary prevention, and to research (Lerner et al. 1993). Much of this work focuses on immigration as a crisis situation (Hertz 1988) that can result in demoralization due to maladjustment and culture shock. Typically, these problems begin in the first year following immigration.

\section{Instruments used in Studies of Immigrants}

Previous studies on immigration have used instruments that tap psychological distress and psychiatric symptomatology but, for the most part, collect little demographic and social information and make no attempt to examine the social and demographic risk factors. The instruments used in previous studies have included: (1) PERI-D, Psychiatric Epidemiology Research Interview Demoralization Scale (Flaherty et al. 1988, Kohn et al. 1989, Zilber et al. 1993); (2) standardized Symptom Check List-90 (SCL-90) (Roskin 1986, Westermeyer et al. 1983) and its short form, Brief Symptom Inventory (BSI), (Aroian et al. 1989); (3) Midtown Psychiatric Impairment Index (Kuo 1976); (4) CES-D scale (Center for Epidemiological Studies Depression scale) (Kuo 1976, Vega et al. 1986); (5) Cornell Medical IndexHealth Questionnaire (Sayil 1984); (6) the Bradburn Morale Scale (Lipson et al. 1989); (7) GHQ General Health Questionnaire (Fichter et al. 1988); (8) Self-Rating Depression Scale (Westermeyer et al. 1983); (9) Cornell Medical Index and Social Readjustment Rating Scale (Masuda et al. 1980); (10) Langner 22 Item Screening Scale of Psychopathology (Cochrane et al. 1977); (11) Social Readjustment Rating Questionnaire (SRRQ) (Schleifer et al. 1979); and (12) Self-Reporting Questionnaire (SRQ) (Upadhyaya et al. 1990). These instruments have been useful in producing descriptive profiles of the psy- 
chological state of immigrants. However, since they do not include questions about current living situation and circumstances before immigration, they have not been able to identify risk factors for psychological distress.

The current study attempted to build the Demographic Psychosocial Inventory (DPSI) as an instrument: (1) to provide a reliable and standardized measure of demographic and background characteristics of immigrants; (2) to measure some dimensions related to psychological distress among immigrants; and (3) to identify immigrants who may need help or who are at risk. This paper describes the instrument, how it is scored, and the results of reliability and validity studies.

\section{Method}

\section{Instrument Development and Description}

Items in the DPSI were derived from the experience of helping many immigrants, and from a review of instruments used in immigrant studies. After two years of pilot testing, DPSI was revised. DPSI consists of 85 selfreport questions, 10 scales, and three general indices. The questions ask about demographic variables, life satisfaction and health before immigration, reasons for immigration, and problems encountered since immigration. There are 14 general demographic questions. The remaining 71 items are grouped into pre-migration and postmigration scales and three general indices in Table 1.

Four scales concern pre-migration: (1) Professional Level (2 items), which assesses vocational level, (2) Immigration Reasons (10 items), which is an inventory of possible reasons that the person immigrated, (3) Pre-migration Life Satisfaction (6 items), which gauges the extent to which the person was satisfied in life before immigrating, and (4) Pre-migration Health Problems (1 item), which asks about pre-migration health.

Six scales and five single items concern post-migration: (1) Distress Sources (17 items), which is an inven- tory of facets of everyday life that cause distress, e.g., housing problems, family problems, language problems, climate, and some personal dimensions such as family problems, personality problems, depression, and anxiety of the future, (2) Commitment to new country (4 items), which assesses a person's commitment to remaining in the country, (3) Job Adequacy ( 2 items), which asks about current employment, (4) Health-Seeking Intentions (15 items), which asks respondents if they are in need of help from any of 15 different health care professionals, (5) Help-Seeking Behaviour, which asks whether a person sought the help of any of five different helping professionals, and (6) Current Health Problems. The single items ask about Conflict Reaction, i.e., distress level when faced with conflict, Unexpected Difficulties, i.e., extent to which difficulties encountered in adjustment were as expected, satisfaction with medical care provider, social support upon arrival in Israel, and whether the person takes sedative or hypnotic drugs. There are three summary indi- ces: Global, Family Strain, and Health Problems.

\section{Scoring, Reliability and Validity}

Scoring of each scale and index is described in the scoring guide that comes with the DPSI. DPSI was tested for reliability of indices and for convergent validity as compared to the PERI-D (Psychiatric Epidemiology Research Interview Demoralization Scale (Dohrenwend et al. 1980), and the BSI (Brief Symptom Inventory) (Derogatis et al. 1982, 1983).

The PERI-D is a 27 -item instrument developed by Dohrenwend and colleagues that measures demoralization. Demoralization has been defined as a predicament for which the person sees no solution (Frank 1973). PERI-D was designed, and has been used, as a screening instrument to measure psychological distress among a wide spectrum of populations (Dohrenwend et al. 1980, 1986; Levav et al. 1991).

PERI-D was designed to tap nonspecific indicators of distress and includes items common to rating scales measuring anxiety, depressive, and psychoso-

Table 1. DPSI Scales and Indices Among Russian Immigrants (n=966)

\begin{tabular}{|c|c|c|c|c|c|c|}
\hline \multirow[b]{2}{*}{ Scale } & \multicolumn{3}{|c|}{ Std. } & \multicolumn{2}{|c|}{ Cronbach's } & \multirow{2}{*}{$\begin{array}{l}\text { Number } \\
\text { of items }\end{array}$} \\
\hline & Mean & Dev. & Min. & Max. & Alpha & \\
\hline \multicolumn{7}{|l|}{ Pre-migration Scales } \\
\hline Professional Level & .94 & .13 & .38 & 1 & .87 & 2 \\
\hline Immigration Reasons & .69 & .16 & .18 & 1 & .41 & 10 \\
\hline \multicolumn{7}{|l|}{ Pre-migration Life } \\
\hline Satisfaction & .71 & .24 & 0 & 1 & .60 & 6 \\
\hline \multicolumn{7}{|l|}{ Pre-migration Health } \\
\hline Problems & .16 & .28 & 0 & 1 & - & 1 \\
\hline \multicolumn{7}{|l|}{ Post-migration Scales } \\
\hline Distress Sources & .52 & .18 & 0 & 1 & .73 & 17 \\
\hline \multicolumn{7}{|l|}{ Commitment to } \\
\hline New Country & .26 & .28 & 0 & 1 & .45 & 4 \\
\hline Job Adequacy & .60 & .18 & 0 & 1 & .23 & 4 \\
\hline \multicolumn{7}{|l|}{ Health-Seeking } \\
\hline Intentions & .20 & .19 & 0 & 1 & .79 & 15 \\
\hline Help-Seeking Behaviour & Ir $\quad .17$ & .19 & 0 & 1 & .44 & 5 \\
\hline Current Health Problems & ns .21 & .30 & 0 & 1 & - & 1 \\
\hline \multicolumn{7}{|l|}{ General Indices } \\
\hline Global & .46 & .11 & .16 & 0.84 & .55 & 70 \\
\hline Family Strain & .47 & .17 & 0 & 1 & .64 & 6 \\
\hline Health Problems & .22 & .15 & 0 & 0.84 & .81 & 25 \\
\hline
\end{tabular}


matic symptoms. It is composed of fixed-format items about the frequency of psychological complaints in the past year. Responses are given on a 5-point scale ranging from "never" to "very often." The higher the PERI-D score, the more pronounced the demoralization.

Reliability and validity tests of PERI-D in the United States and Israel have found satisfactory results (Dohrenwend et al. 1986). It has been widely used in Israel (Fenig et al. 1991, Flaherty et al. 1988, Gilboa et al. 1990, Lerner et al. 1991, Zilber et al. 1993).

The BSI (Brief Symptom Inventory) provides a finer assessment of the severity and nature of psychological distress than the PERI-D. A shortened version of the better known Hopkins Symptom Checklist, SCL-90 (Derogatis et al. 1982, 1983), it is a 53item self-report inventory. The subjects respond on a 5-point scale from "not at all troubled by ... during the last year" to "troubled a lot by ... in the last year" to a list of psychological symptoms. The analysis of BSI scores supplies quantitative indices of severity of distress and profiles that correspond to standard clinical syndromes.

Reliability and validity tests of BSI have found satisfactory results. Reliability of the 9 symptoms and the three global indices have been tested for in- ternal consistency that ranged from Alpha 0.71 to 0.80 . Test-retest coefficients ranged from 0.68 to 0.90 .

\section{Subjects}

The DPSI, PERI-D, and BSI were administered to two groups of adult immigrants who came to Israel since 1989. The first group consisted of a convenience sample of 966 immigrants aged 18 to 87 in Jerusalem, Tel Aviv, and Beer-Sheva. They were administered study instruments between 1991 and 1993. Respondents were from typical immigrant gathering places, e.g., professional retraining courses, temporary accommodations at hotels, social services for immigrants, and Hebrew-language instruction courses. At each site data were collected from approximately $75 \%$ of the immigrants present at the time. On average, respondents were 39.3 years old (st. dev. 12.9). About $54 \%$ had immigrated within 12 months of the study, $42 \%$ within 1 to 2 years, and $4 \%$ within 25 to 30 months. The average time in Israel was 12.5 (st. dev. 7.8) months. The male/female ratio was 1:1.4. About $67 \%$ were married, $13 \%$ single, $19 \%$ divorced and widowed, and $1 \%$ unknown. About $80 \%$ were university graduates, $13 \%$ had vocational training, $5 \%$ were high school graduates, and $2 \%$ had grade-school education.

\begin{tabular}{|c|c|c|c|c|c|c|}
\hline \multicolumn{7}{|c|}{ Table 2. DPSI Items with Gender Differences in Responses } \\
\hline & \multicolumn{2}{|c|}{ Males } & \multicolumn{2}{|c|}{ Females } & \multirow[b]{2}{*}{ t } & \multirow[b]{2}{*}{$\mathbf{p}$} \\
\hline Scale & Mean & Std. Dev. & Mean & Std. Dev. & & \\
\hline \multicolumn{7}{|l|}{ Pre-migration Scales } \\
\hline Immigration Reasons & .67 & .17 & .71 & .15 & 3.50 & .000 \\
\hline \multicolumn{7}{|l|}{ Post-migration Scales } \\
\hline Distress Sources & .49 & .18 & .53 & .18 & 3.60 & .000 \\
\hline Job Adequacy & .62 & .19 & .58 & .17 & 3.73 & .000 \\
\hline Health-Seeking Intentions & s .17 & .20 & .21 & .19 & 3.48 & .001 \\
\hline Help-Seeking Behaviour & .15 & .19 & .19 & .19 & 2.81 & .005 \\
\hline \multicolumn{7}{|l|}{ General Indices } \\
\hline Global & .44 & .11 & .47 & .11 & 3.50 & .000 \\
\hline Family Strain & .44 & .15 & .49 & .18 & 4.60 & .000 \\
\hline Health Problems & .18 & .29 & .23 & .31 & 2.68 & .007 \\
\hline \multicolumn{7}{|l|}{ Single Items } \\
\hline Use Sedative Drugs & .21 & .41 & .32 & .46 & 3.50 & .000 \\
\hline Conflict Reaction & .66 & .35 & .76 & .31 & 4.99 & .000 \\
\hline Unexpected Difficulties & .50 & .47 & .56 & .47 & 2.05 & .040 \\
\hline
\end{tabular}

The second group consisted of 125 psychiatric outpatient immigrants with mental disorders, and 250 respondents who were matched with outpatients for age, gender, and time in Israel. Most of the outpatients had had at least one psychiatric. hospitalization. In addition to completing the study instruments, patients had a complete physical examination, and were interviewed by two psychiatrists who used psychiatric rating scales (Brief Psychiatric Rating Scale, Hamilton Depression Scale).

\section{Results}

The mean scores, range on indices, and reliability as measured by Cronbach's Alpha are presented in Table 1. As can be seen, Professional Level, Pre-migration Life Satisfaction, Distress Sources, Health-Seeking Intentions, Family Strain, and Health Problems indices had Cronbach's Alpha reliability coefficients of at least .60, indicating a high degree of internal consistency. The Global Index almost reaches .60 level. Subjects found the DPSI easy to use and understand.

As shown in Table 2, there are statistically significant gender differences on six scales and three general indices and on two single questions. Females had more Immigration Reasons, Conflict Reactions (a measure of emotional reactivity to conflict situations), Distress Sources, Health-Seeking Intentions, Help-Seeking Behaviour, Family Strain, Health Problems, Unexpected Difficulties, i.e., greater discrepancy between actual difficulties encountered and those expected, use of sedative drugs, and a higher global index, than males. Females had less Job Adequacy than males.

Pearson's product-moment correlations between all DPSI scales, indices, and single items with correlations greater than .30 are presented in Table 3. Where differences in correlations for males and females existed, they were indicated with female correlation preceding male correlation. For example, Pre-migration Health Problems were less highly correlated for women (.37) than for men (.49) with current health 


\begin{tabular}{|c|c|c|c|c|c|c|c|c|}
\hline DPSI Dimensions & PL & PMH & DS & HSI & HSB & CHP & HPI & GI \\
\hline Pre-migration Health & $-/-.31$ & 1 & - & - & .39 & $.37 / .49$ & $.48 / .37$ & .41 \\
\hline Distress Sources & -1.30 & - & 1 & .34 & - & - & .41 & .56 \\
\hline Commitment to New Country & - & - & - & - & - & - & - & .34 \\
\hline Health-Seeking Intentions & - & $.33 /-$ & .34 & 1 & $.33 /-$ & - & .92 & $.43 / .30$ \\
\hline Help-Seeking Behaviour & - & .39 & - & $.33 /-$ & 1 & .46 & .60 & .42 \\
\hline Current Health Problems & - & .42 & - & .40 & $.39 / .49$ & 1 & .46 & .42 \\
\hline \multicolumn{9}{|c|}{$\begin{array}{l}\text { Notes: Coefficients for females/males presented if there is more than .10 difference between them, or the appropriate coefficient is } \\
\text { missing. Single coefficients are males and females together. PL-professional level, PMH - premigration health, DS - distress } \\
\text { sources, HSI - health-seeking intentions, HSB - help-seeking behaviour, CHP - current health problems, } \\
\text { HPI - health problem index, GI - global index }\end{array}$} \\
\hline
\end{tabular}

problems. In a few cases, e.g. Professional Level and Pre-migration Health and Distress Sources, there was only a meaningful correlation for females. As can be seen, Global and Health Problem indices were the most highly correlated with the other indices. This was expected since these indices include many of the scales.

We examined the relationship between the DPSI items, scales, indices, age, and length of time in Israel. The following had correlations with age greater than $r=.25$ : Pre-migration Health Problems ( $r=.40)$, Current Health Problems $(r=.29)$, Global Index $(\mathrm{r}=.32)$, and Health Problem Index $(r=.30)$. Only Job Adequacy Index was correlated with time in Israel $(r=.25)$.

\section{Comparison of Psychiatric Outpatients and Non-patients}

We compared the results of scale and single items for 125 psychiatric outpatients and 231 immigrants who were not known to be in psychiatric treatment. (Because of some minor changes in the DPSI scoring, these means cannot be compared to the first group means as presented in Table 1.) We found the following significant differences $(p<.05)$ in means using t-tests: patients had fewer Immigration Reasons (.27) than did controls (.29), lower Pre-migration Life Satisfaction (.56 vs. .39), more Pre-migration Health Problems (.66 vs. .39), more Distress Sources (.57 vs. .51), more Current Health Problems (.92 vs. .49), and more
Help-Seeking Behaviour (.50 vs. .2). In general, the outpatients tended to have had more life difficulties prior to immigration and more difficulties since coming to Israel than the non-patients.

\section{Validity}

To validate the DPSI we compared it to concurrent PERI-D and BSI scores. We used both instruments because the BSI measures specific symptoms and the PERI-D measures generalized distress. We examined correlations between DPSI scales and PERI-D. Five scales correlated greater than $r=.25$ with PERI-D. These were: Distress Sources $(\mathrm{r}=.49)$, Help-Seeking Intentions $(\mathrm{r}=.30)$, Help-Seeking Behaviour $(\mathrm{r}=.28)$, Global index $(\mathrm{r}=.53)$ and

Table 4. Selected Pearsonian Correlations (above $\mathrm{r}=.3$ ) of DPSI and BSI Dimensions.

\begin{tabular}{|c|c|c|c|c|c|c|c|c|c|c|}
\hline DPSI/BSI Scales & Smzn & Obs. C. & IS & Depr. & Anx. & PI & Host. & Psych. & PA & GSI \\
\hline Distress Sources & .37 & - & -.35 & .41 & .43 & - & .30 & $.31 /-$ & - & .44 \\
\hline Health Seeking intentions & $.38 /-$ & $.31 /-$ & - & - & 一 & - & - & - & - & $.32 /-$ \\
\hline Help Seeking Behaviour & .34 & - & - & - & - & - & - & - & - & - \\
\hline Pre-migration Health & .37 & - & - & - & - & - & - & - & - & - \\
\hline Health Index & .45 & .36 & - & $.30 /-$ & $.34 /-$ & - & - & $.32 /-$ & $.32 /-$ & .39 \\
\hline Current Health Problems & $.34 /-$ & & - & - & - & - & - & - & - & 一 \\
\hline Global Index & .46 & .38 & $-/ .38$ & .48 & .49 & .33 & .32 & $.35 /-$ & - & .50 \\
\hline \multicolumn{11}{|c|}{$\begin{array}{l}\text { Notes: Coefficients for females/males presented if there is more than .10 difference between them, the appropriate coefficient is } \\
\text { missing. Single coefficients are males and females together. Smzn - somatization, Obs. C - obsessive compulsive, } \\
\text { IS - Interpersonal sensitivity, Depr. - depression, Anx. - anxiety, PI - paranoid ideation, Host - hostility, Psych - psychotocism, } \\
\text { PA - phobic anxiety, GSI - global severity index. }\end{array}$} \\
\hline
\end{tabular}




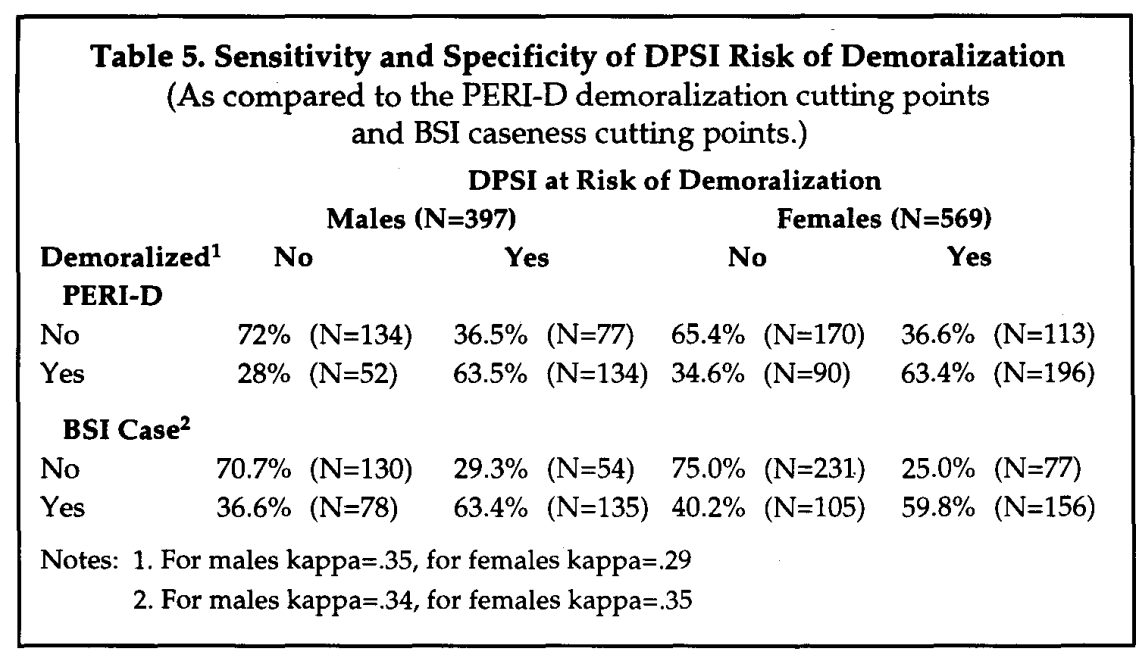

Health Problem index $(r=.41)$. An analysis of the correlation of DPSI and BSI scales is presented in Table 4. As can be seen, the Global index, Distress Sources, and Health Index were the most highly correlated with BSI scales. The BSI Somatization index is the most highly correlated with DPSI scales, followed by the BSI Global Severity Index.

\section{DPSI Risk Cutting Points}

To see to what extent DPSI was helpful in identifying people who were at risk of being demoralized, or at risk of psy- chopathology, we established DPSI cutting points relative to the PERI-D demoralization cutting points [1.23 males, 1.51 females (Fenig et al. 1991, Gilboa et al. 1990) based on Shrout et al. (1986)], and psychopathology cutting points of BSI [GSI=.58 males, .78 females (Derogatis et al. 1982, 1983)]. For the PERI-D, we found that the optimal DPSI Global ind ex cutting points were .42 for males and .44 for females, which we call "at risk of demoralization." According to PERI-D, 47\% of males and $50 \%$ of females were demoralized. According to DPSI, 53\% of males and $54 \%$ of females were at risk of demoralization. The comparison in identifying cases between DPSI and PERI-D is presented in Table 5. It will be seen that DPSI cutting points recognize about $63 \%$ of males and females who are demoralized according to PERI-D, and a combined average of about $68 \%$ (males $=72 \%$, females $=62 \%$ ) of those who are not demoralized. DPSI tends to recognize slightly more cases as being at risk of demoralization than the number of those who are demoralized according to PERI-D.

We developed similar cutting points relative to the BSI psychopathology cutting points. The DPSI Global index cutting points that best corresponded with BSI cutting points were .44 for males and .48 for females. According to BSI $46 \%$ of males and $54 \%$ of females were "cases." The comparison in identifying cases is presented in Table 5. As can be seen, DPSI cutting points recognize a combined average of males and females of about $61 \%$ of those who are cases according to BSI, and an average of about $72 \%$ of those who are not cases according to BSI. DPSI tends to recognize slightly fewer respondents as being cases than those who are cases according to BSI.

Table 6. Multiple Regression Models Predicting PERI-D Score and BSI Global Severity Index (Using DPSI Indices and single items not included in indices)

\begin{abstract}
Variable or Index
Distress Sources

Conflict Reaction

Take sedatives or hypnotics

Help-Seeking Behaviour

Unexpected Difficulties

Immigration Reasons

Health-Seeking Intentions

Commitment to New Country

Pre-migration Life Satisfaction

Relatives in Israel

Pre-migration Health Problems

Professional Level

Constant
\end{abstract}

\begin{tabular}{cccr}
\multicolumn{4}{c}{ PERI-D Score } \\
Model 1 & \multicolumn{2}{c}{ Model 2 } \\
Males & & \multicolumn{2}{c}{ Females } \\
B & $\mathbf{R}^{2}=.38$ & $\mathbf{R}=.59$ & $\mathbf{R}^{2}=.35$ \\
.95 & Beta & B & Beta \\
.36 & .30 & 1.04 & .29 \\
.14 & .22 & .37 & .17 \\
.45 & .09 & .19 & .13 \\
.16 & .14 & .37 & .11 \\
- & .13 & .16 & .11 \\
- & - & - & - \\
- & - & .39 & .11 \\
- & - & .26 & .09 \\
.19 & - & - & - \\
.19 & .15 & - & - \\
- & - & - & - \\
.29 & - & .32 &
\end{tabular}

\begin{tabular}{cccc}
\multicolumn{3}{c}{ BSI Global Severity Index } \\
Model 3 & \multicolumn{2}{c}{ Model 4 } \\
Males & Females \\
B $=.60$ & $\mathbf{R}^{2}=.36$ & R=.57 & $\mathbf{R}^{2}=.33$ \\
B & Beta & B & Beta \\
.86 & .31 & .78 & .25 \\
.31 & .21 & .28 & .15 \\
- & - & .13 & .10 \\
.44 & .16 & .44 & .14 \\
.10 & .09 & .14 & .11 \\
.49 & .17 & .34 & .09 \\
- & - & .35 & .11 \\
.16 & .09 & .22 & .11 \\
-.24 & -.11 & - & - \\
.16 & .14 & - & - \\
- & - & - & - \\
- & - & -.48 & -.10 \\
.27 & & .10 &
\end{tabular}

Refuge, Vol. 14, No. 9 (February 1995) 
The next two models predict the BSI Global Severity Index based on DPSI scales and single items not included in scales. As can be seen in Table 6, using 9 variables for males and 8 for females, we obtained an $R^{2}$ above 0.32 . The models for males and females are similar.

\section{Discussion and Conclusion}

The results suggest that DPSI is a promising instrument for collecting descriptive information about immigrants and for detecting psychological distress. The strong relationship between DPSI, PERI-D, and BSI suggests that DPSI is able to tap levels of psychological distress in the process of assembling a psychosocial profile of immigrants. The results suggest some factors that are particularly salient in developing psychological distress. The greatest risk factors of demoralization are a greater number of distress sources, difficulty in dealing with conflict, greater discrepancy between actual difficulties encountered and those expected, and more reasons for immigration. The single most important variable in predicting demoralization caseness was the number of distress sources.

The major difference between the DPSI, PERI-D, and BSI is that PERI-D and BSI measure a person's state of being based on behaviour, while DPSI helps to identify reasons for a person's state of being and thereby helps to identify at-risk groups because it taps items that are precursors of demoralization. DPSI is designed to help learn about stressors and life events specific to immigration, and their relationship to demoralization.

DPSI is a promising instrument for gathering demographic and background characteristics of immigrants, and psychosocial risk factors for development of demoralization. We are constantly adding new subjects to our database of immigrants. Future research is being planned to learn more about the psychosocial adjustment of immigrants.

\section{Notes}

1. Authors thank A. Ponizovsky, A. Sheinin, A. Factourovich, K. Levin, A. Segal, M. Chemelevsky, A. Mizrukhin, and $F$. Zetser who participated in data collection. We are grateful to Dr. Y. Schultz (Director of Psychological Support Project "Maavar") and to Professor Y. Ginath (Director of Talbieh Mental Health Center) for their support and contributions at all stages of the study.

\section{References}

Aroian, K. J., and C. A. Pastdaughter. 1989. "Multiple-method, cross cultural assessment of psychological distress." Image J. Nurs. School, 21: 90-93.

Bagheir, A. 1992. "Psychiatric problems among Iranian immigrants in Canada." Canadian Journal of Psychiatry, 37: 7-11.

Barankin, T., Konstantareas, M. M., and F. de Bosset. 1989. "Adaptation of recent Soviet Jewish immigrants and their children to Toronto." Canadian Journal of Psychiatry, 34: 512-18.

Beiser, M. 1988. "Influences of time, ethnicity, and attachment on depression in Southeast Asian refugees." American Journal of Psychiatry, 145: 46-51.

Berry, J. 1979. "Social and cultural change." In H.C. Traindis and R. Brislin (Eds.) Handbook of Cross-Cultural Psychology, Vol 5., Boston: Allyn and Bacon.

Brodsky, B. 1988. "Mental health attitudes and practices of Soviet Jewish immigrants." Health and Social Work, 13: 13036.

Cochrane, R., F. Hashmi, and M. R. Ropes. 1977. "Measuring psychological disturbance in Asian immigrants to Britain." Social Science and Medicine, 11: 157-64.

Dean, G., D. Walsh, H. Downing, and S. Emer. 1981. "First admissions of nativeborn and immigrants to psychiatric hospitals in South East England." British Journal of Psychiatry, 139: 505-12.

Derogatis, L. R., and P. M. Spenser. 1982. The BriefSymptom Inventory (BSI): Administration, Scoring and Procedures Manual. Baltimore, MD: Johns Hopkins University School of Medicine.

Derogatis, L. R., and N. Melisavatos. 1983. "The Brief Symptom Inventory: An Introductory Report." Psychological Medicine, 3: 595-605.

Dohrenwend, B. P., P. E. Shrout, E. Galdys and F. S. Mendelsohn. 1980. "Nonspecific psychological distress and other dimensions of psychopathology." Archives of General Psychiatry, 37: 1229-36.
Dohrenwend, B. P., I. Levav, and P. E. Shrout. 1986. "Screening scales from the Psychiatric Epidemiology Research Interview (PERI)." In M. M. Weissman, J. K. Myers, and C. E. Ross (eds.), Community surveys of psychiatric disorders (pp. 349-76). New Brunswick, NJ: Rutgers University Press.

Epstein, A. (1992). The Impact of Time in Israel and Jewish Identity on the Psychological Adjustment of Recent Soviet Immigrants to Israel. Unpublished Doctoral Dissertation, Yeshiva University, New York.

Fenig, S., and I. Levav 1991. “Demoralization and social support among Holocaust survivors." Journal of Nervous and Mental Disease, 179(3): 167-72.

Fichter, M. M., M. Elton, M. Diallina, I. G. Koptagel, W. E. Fthenakis, and S. Weyerer. 1988. "Mental illness in Greek and Turkish adolescents." European Archives of Psychiatry and Neurological Science, 237: 125-34.

Flaherty, J. A., R. Kohn, A. Golbin, M.Gaviria, and B. Birz. 1986. "Demoralization and social support in Soviet-Jewish Immigrants to U.S." Comprehensive Psychiatry, 27: 149-58.

Flaherty, J. A., R. Kohn, I. Levav, and S. Birz. 1988. "Demoralization in Soviet-Jewish immigrants to the United States and Israel." Comprehensive Psychiatry, 29(6): 588-97.

Frank, J. 1973. Persuasion and healing. Baltimore: Johns Hopkins University Press.

Gilboa, S., I. Levav, L. Gilboa, and F. Ruiz. 1990. "The epidemiology of demoralization in a kibbutz." Acta Psychiatrica Scandinavica, 82: 60-64.

Glover, G. R. 1991. “The use of inpatient psychiatric care by immigrants in a London borough." International Journal of Social Psychiatry, 37: 121-134.

Grinberg, L., and R. Grinberg. 1989. Psychoanalytic Perspectives of Migration and Exile. New Haven: Yale University Press.

Grove, W. M., P. J. Clayton, J. Endicott, R. M. Hirschfield, et al. 1986. "Immigration and major affective disorder." Acta Psychiatrica Scandinavica, 74: 548-52.

Harrison, G. 1990. "Searching for causes of schizophrenia: The role of migrant studies." Schizophrenia Bulletin, 16(4): 663-71.

Hartman, M., and H. Hartman. 1986. "International migration and household conflict." Journal of Comparative Family Studies, 17: 131-38.

Hertz, D. G. 1988. "Lost and Found: Patterns of Migration and Psychological and Psychosocial Adjustment of Migrants." Acta Psychiatrica Scandinavica, 78: 159-65.

Horowitz, R., and M. Popper. 1992. Psychiatric Hospitalization of Immigrants 1990-1991 
(Statistical Report \#7). Jerusalem: Israel Ministry of Health, Mental Health Services, Department of Information and Evaluation.

Itzigsohn, J., and S. Minuchin-Itzigsohn. 1989. "Depressive process connected to aliya and migration and their cognitive treatment according to A. Beck." In Brief Psychotherapy: Background, Techniques and Application. Jerusalem: Magnes Press.

Jayasuriya, L., D. Sang, and A. Fielding. 1992. Ethnicity, Immigration and Mental Illness: A Critical Review of Australian Research. Canberra: Bureau of Immigration Research, Australian Government Publishing Service.

Kohn, R., J. A. Flaherty, and I. Levav. 1989. "Somatic symptoms among older Soviet Immigrants: An Exploratory Study." International Journal of Social Psychiatry, 35: 350-60.

Kuo, W. 1976. "Theories of migration and mental health: An empirical testing of Chinese-Americans." Social Science and Medicine, 10: 297-306.

Kuo, W., H. Tsai, and M. Yung. 1986. "Social networking, hardiness and immigrants' mental health." Journal of Health and Social Behavior, 27: 133-49.

Lerner, J., and N. Zilber. (1991). Psychological distress among Soviet immigrants before and after the Gulf war Presented at WHO Symposium on Psychiatric Epidemiology, Oslo, July 1991.

Lerner, J., J. Mirsky and M. Barasch. 1993. "New beginnings in an old land: The mental health challenge in Israel," In A. J. Marsella, T. Bornemann, S. Ekblad, and J. Orley (eds.), Amidst Peril and Pain: The Mental Health and Well Being of the World's Refugees. Washington, DC: American Psychological Association Press.

Levav, I., R. Kohn, J. Flahertry, Y. Lerner, and E. Aisenberg. 1990. "Mental Health Attitudes and Practices of Soviet Immigrants." Israel Journal of Psychiatry and Related Sciences, 27: 131-44.

Levav, I., S. Gilboa, and F. Ruiz. 1991. "Demoralization and gender differences in kibbutz." Psychological Medicine, 21: 1019-28.

Lipson, J., G. Meleis, and I. Afaf. 1989. "Methodological issues in research with immigrants." Medical Anthropology, 12: 103-15.

Masuda, M., K. Lin, and L. Tazuma. 1980. "Adaptation problems of Vietnamese refugees: II. Life changes and perception of life events." Archives of General Psychiatry, 37: 447-50.

Mavreas, V., and P. Bebbington. 1990. "Acculturation and psychiatric disorder: $\mathrm{A}$ study of Greek Cypriot immigrants." Psychological Medicine, 20: 941-51.

May, K.M. 1992. “Middle-Eastern immigrant parents' social networks and help-seeking for child health care." $J$. Adv. Nurs., 17: 905-12.

Noh, S., Z. Wu, M. Speechley and V. Kaspar. 1992. "Depression in Korean immigrants in Canada: II. Correlates of gender, work, and marriage." Journal of Nervous and Mental Disease, 180: 578-82.

Ponizovsky, A., Y. Ginath, and M. Ritsner. 1994. "Family instability, immigration and suicide ideation." Paper presented at The Family on the Threshold of the 21st Century: Trends and Implications, Jerusalem, Israel, June.

Rack, P. H. 1988. "Psychiatric and social problems among immigrants. Berzelius Symposium XI: Transcultural psychiatry." Acta Psychiatrica Scandinavica, 78: 167-73.

Ring, J. M., and P. Marquis. 1991. “Depression in a Latino immigrant medical population: An exploratory screening and diagnosis." American Journal of Orthopsychiatry, 61: 298-302.

Ritsner, M., A. Ponizovsky, S. Safro, Y. Schultz, and Y. Ginath. 1993. "Demoralization Among Soviet Immigrants and Zionist Forum Support: First year experience of psychological support project." Research Report, Talbieh Mental Health Center, Jerusalem, Unpublished.

Ritsner, M., and Y. Ginath. 1994. "Emotional distress among immigrants from CIS, 1989-1993." Paper presented at Israel Psychiatric Association Eighth Annual Convention, Tiberias. May.

Rodriguez, R., and A. DeWolfe. 1990. "Psychological distress among MexicanAmerican and Mexican women as related to status in the new immigration law." Journal of Consulting and Clinical Psychology, 58: 548-53.

Roskin, M. 1986. "Psychosocial transitions: an emotional health comparison." International Journal of Social Psychiatry, 32: 3947.

Sayil, I. 1984. "Psychiatric problems of Turkish labourers in Holland." International Journal of Social Psychiatry, 30(4): 267-73.

Schleifer, S. J., A. H. Schwartz, J. C. Thornton, and S. L. Rosenberg. 1979. "A study of American immigrants to Israel utilizing the SRRQ." Journal of Psychosomatic Research, 23: 247-52.

Scott, W., and R. Scott. 1989. Adaptation of Immigrants: Individual Differences and Determinants. Oxford: Pergamon Press.

Shrout, P.E., B. P. Dohrenwend, and I. Levav. 1986. "A discriminant rule for screening cases of diverse diagnostic type: preliminary results." Journal of Consulting and Clinical Psychology, 54: 314-19.

Stack, S. 1981. "Comparative analysis of immigration and suicide." Psychological Reports, 49: 509-10.

Trovato, F. 1986. "A time series analysis of international immigration and suicide mortality in Canada." International Journal of Social Psychiatry, 32: 38-46.

Upadhyaya, A., F. Creed and M. Upadhyaya. 1990. "Psychiatric morbidity among mothers attending well-baby clinic: $\mathrm{A}$ cross-cultural comparison." Acta Psychiatrica Scandinavica, 81: 148-51.

Vega, W. A., B. Kolody, J. R. Valle, and R. Hough. 1986. “Depressive symptoms and their correlates among immigrant Mexican women in the United States." Social Science and Medicine, 22: 645-52.

Westermeyer, J. et al. 1983. “Migration and mental health among Hmong refugees: Association of pre- and post-migration factors with self-rating scales." Journal of Nervous and Mental Disease, 171: 92-96.

Weyerer, S., and H. Hafner. 1992. "The high incidence of psychiatrically treated disorders in the inner city of Mannheim: Susceptibility of German and foreign residents." Social Psychiatry and Psychiatric Epidemiology, 27: 142-46.

Wijesinghe, C. P., and D. J. Clancy. 1991. "Schizophrenia in migrants living in the western region of Melbourne." Australian and New Zealand Journal of Psychiatry, 25: $350-57$

Williams, C. L., and J. W. Berry. 1991. "Primary prevention of acculturative stress among refugees. Application of psychological theory and practice." American Psychologist, 46: 632-41.

Zilber, N., and Y. Lerner. 1993. "The psychological distress of Soviet immigrants to Israel; risk/factors, influence of the Gulf War." Paper presented at Regional Meeting of the International Epidemiological Association, Jerusalem, February. $J$

\section{Asylum- A Moral Dilemma}

$$
\begin{aligned}
& \text { A thought-provoking } \\
& \text { analysis on refugees } \\
& \text { by W. Gunther Plaut. }
\end{aligned}
$$

Available in Spring '95. 
Refuge

York Lanes Press

Centre for Refugee Studies

Suite 351, York Lanes

York University

4700 Keele Street, North York

Ontario, Canada M3J 1P3

Phone: (416) 736-5843

Fax: (416) 736-5837

Internet: refuge $@ v m 1 . y o r k u . c a$

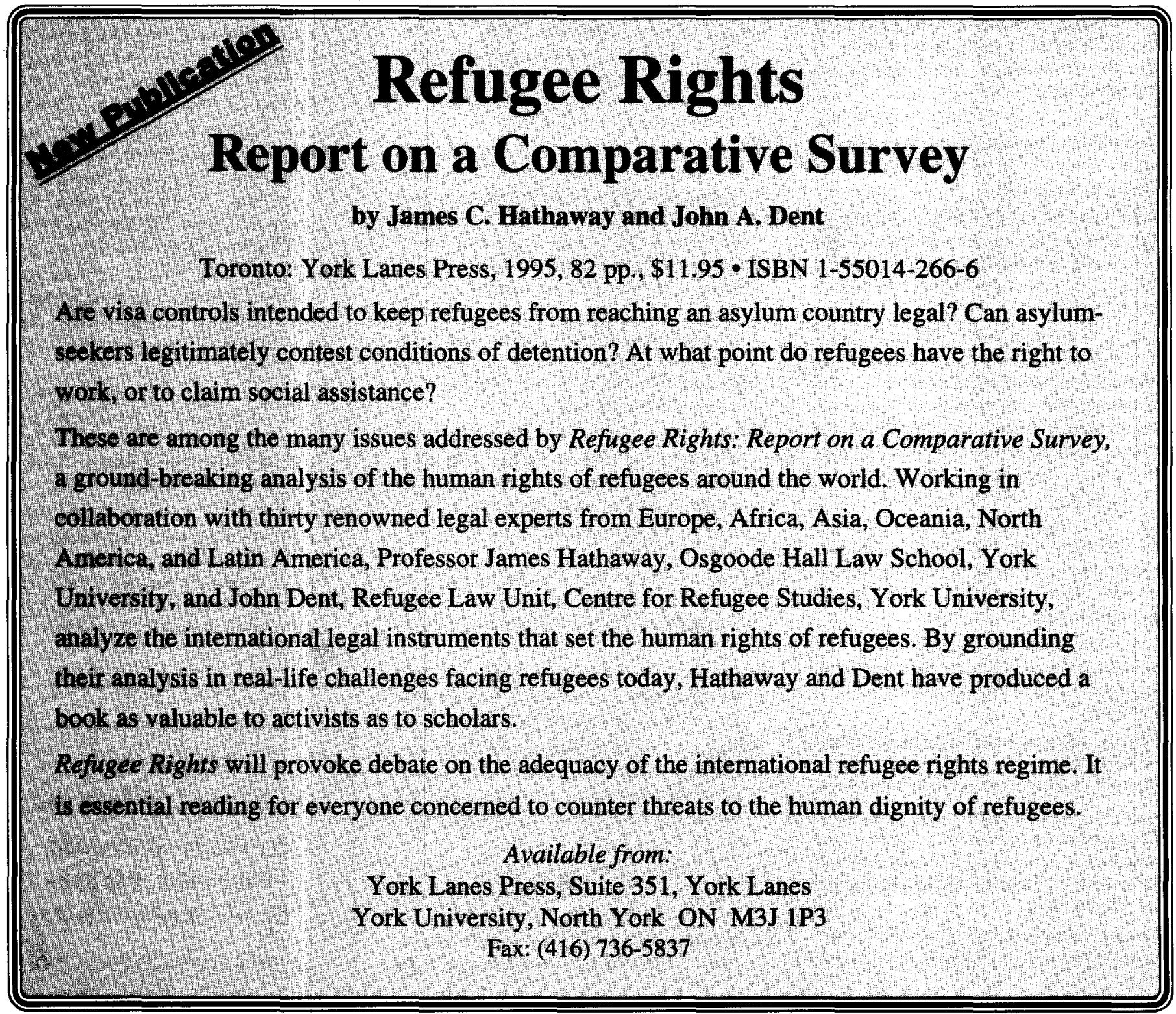

